\title{
ATLANTIS IN SPAIN
}

\author{
Papamarinopoulos S.P. \\ University of Patras, Department of Geology, Patra, Greece
}

\section{Part I: Plato science and mythology}

\begin{abstract}
Dealing with Plato's Atlantis one should be aware that its author is the very first person in the world who defined science's and mythology's concepts. However, he introduced several times paramyths in his dialogues and he encrypted in them moral, philosophical, political, mathematical, musicological information and other ideas. Such a person wrote the famous Atlantis story. We shall attempt desipher fully in the successive texts but before we do that we need to familiarize the reader in order to understand the breaking of a 2400 years complexity which will be presented through the Hellenic Geological Society's $12^{\text {th }}$ International Symposium organized by the Patras University Department of Geology.
\end{abstract}

\section{Introduction}

Many analysts have entirely rejected Timaeos and Critias as a possible source of any useful historical information. These experts did not really take into account that Plato defined science in his dialogue Phaedros (Phaedros 277.b.5 - 277.c.3) and mythology in his dialogue Timaeos (Criti 110.a.3-110.a.4.). Besides, he has divided the myths in genuine (Tim 26.e.4-26.e.5) and in fabricated ones (Resp 377.b.5377.b.6.). He made great use of the latter in all his dialogues sending messages to his readers for morality, philosophy, politics and sometimes he encrypted, for his own reasons, mathematical theorems or relations within paramythical (fabricated myths) stories. A good example is what Vardulakis and Pugh (2008) found in the Laws in connection with the prime numbers.

\section{Plato and Science}

Plato initially defined science for first time in the world in Phaedros as follows:

Phaedr 277.b.5-277.c.3

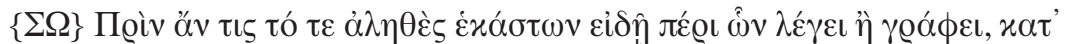

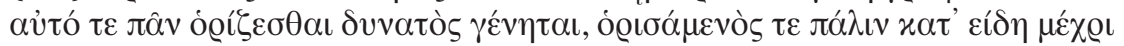

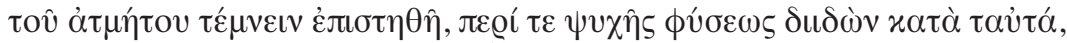

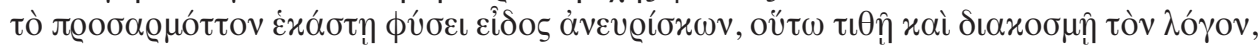

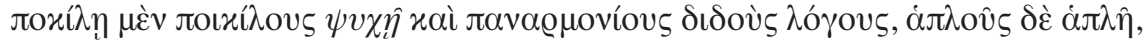

Socrates: "First you must know the truth about the subject that you speak or write about, that is to say, you must be able to isolate it in definition, and having so defined it you must next understand how to divide it into kinds, until you reach the limit of division, secondly, you must have a corresponding discernment of the nature of the soul, discover the type of speech appropriate to each nature, and order and arrange your discourse accordingly, express the nature of the complex and simple soul with panarmonic and simple analogies" 
Hamilton and Cairns (1980) say that Plato and Descartes, 2000 years apart, expressed almost the same sequential order of mental operations with similar concepts. In Plato's Phaedrus, we find suggestions about the art of speech writing that bear a striking similarity to the four rules of investigation (examination, division, order and enumeration) that are enunciated as the substance of Descartes' Discourse on method.

But Plato does not stop here. Moreover he also defines the concept of mythology in Critias as follows:

Criti 110.a.2-110.a.4

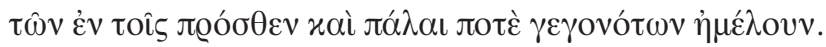

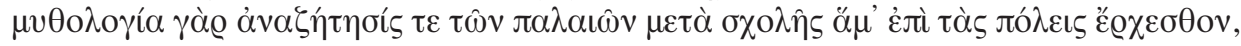

"and their talk was about them; and in consequence they paid no regard to the happenings of bygone ages. For legendary lore and the investigation of antiquity are visitants that come to cities"

He then defines the genuine and fabricated myth's concept respectively. He offers no ambiguity to his reader that he does know what he says and why he describes. He offers the definitions as follows:

\section{Plato on genuine myth}

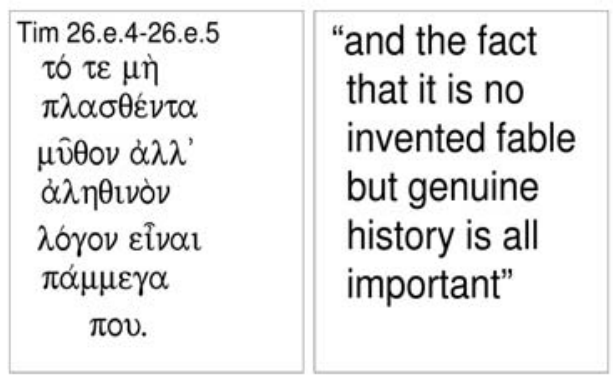

Plato on fabricated myth

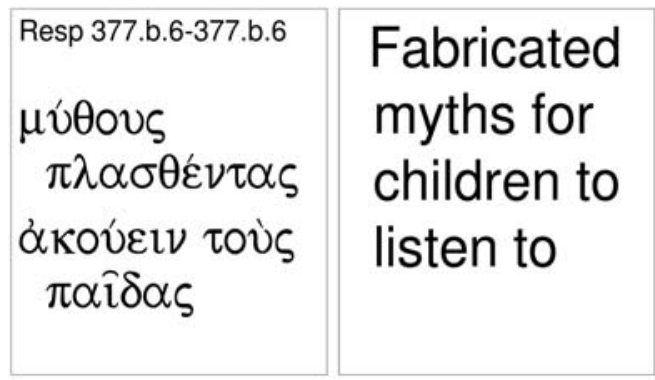

We shall demonstrate to the reader in Part II (Papamarinopoulos, 2010b) that half of Timaeos and Critias in connection with prehistoric Athens was not an imaginary entity but a reality unknown to the historians like Herodotus and Thucydides and yet it was described only by the non-historian Plato. The latter did not have any possibility to know Athens of the $12^{\text {th }}$ century B.C. being a citizen of Athens in the $4^{\text {th }}$ century B.C. of course. Then we shall demonstrate to the reader what, and where and when and how Atlantis was perished in 24 hours in Part III, IV,V and VI.

Figure 1 illustrates how the reader can differentiate geometrically the difference between the genuine and fabricated myth's structure. The genuine myth contains always a kernel of history in its center which can be tested and control-led tran-scientifically. However, it is encapsulated by the successive inventions of the centuries from the initial oral transmitters, from generation to generation, to the time the myth was recorded in a writing system. This spherical sectors does not offer anything reliable to science's scrutiny. The paramyth contains no information in connection with history.

\section{Conclusions}

Plato's dialogues contain exceptional information in a variety of scientific fields. However, Timaeos and Critias, contains the famous case of Atlantis which is proposed, by the author, to the scientific community as a unique historic reality. Fig. 2 shows the difference of Atlantis' case in comparison to the, historic event, genuine myth and paramyth. To the top (left) the historic event is shown. To the top (right) the genuine myth is shown. To the bottom (left) the paramyth is shown containing no historic information. To the bottom (right) a platonic addition is shown as the most external spherical sector en- 


\section{Myth (left) and paramyth (right)}
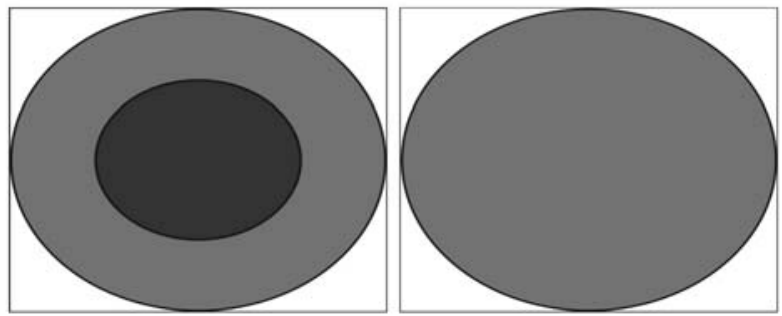

Fig. 1: The genuine myth (left) contains a kernel of historic reality which can be proved scientifically assuming one removes surgically the spherical sector which has been added on it through the eons from the oral transmitters of a past physical event from generation to generation. The fabricated myth or paramyth (right) may encrypts interesting information but without containing any historic significance.

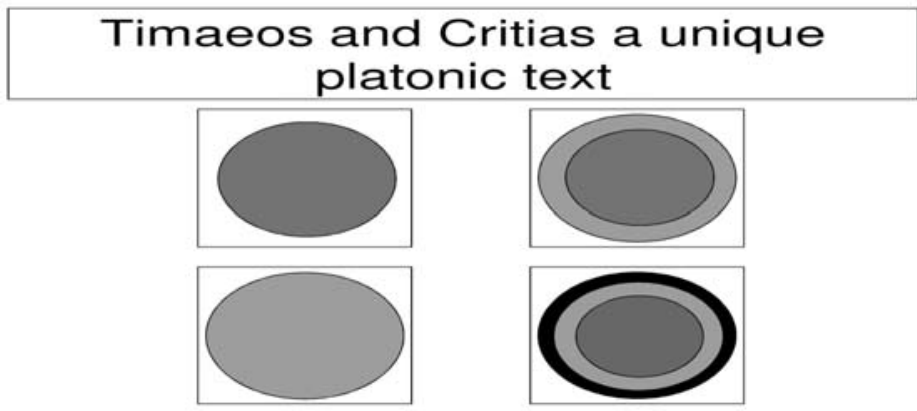

Fig. 2: In top (left) a historic event is shown. Plato knew history but he was not a historian. In bottom (left) a paramyth is shown. Plato made great use of many paramyths which did not contain any historic content. In top (right) a genuine myth is shown containing a historic kernel. In bottom (right) the Atlantis story is shown. It is a genuine myth as in top (right) encapsulated by a platonic black spherical sector containing mathematics.

capsulating an otherwise genuine myth. The platonic addition on Atlantis has been manifested by Brumbaugh (1954) in his famous book on Plato's mathematical imagination.

\section{References}

Brumbaugh, R.S., 1954. Plato's mathematical imagination.'The mathematical passages in the dialogues and their interpretation". Indiana University Press, p.p.302.

Decartes, R., 1967. Le discours de la method. Pataud, J.M. (Ed)., Paris: Bordas.

Hamilton, E., and Cairns, H. (Eds.), 1980. Plato: The Collected Dialogues. Bollingen Series. Princeton: Princeton University Press.

Papamarinopoulos, St.P., 2010b. Atlantis in Spain. Part II: The case of prehistoric Athens Proceedings of the current volume of the $12^{\text {th }}$ International Symposium of the Hellenic Geological Society, May 1922. Organiser University of Patras.. Department of Geology.

Plato.

Vardulakis,A. and Clive Pugh., 2008. Plato's hidden theorem on the distribution of primes. Springer Science, Volume 30, No 3, p.p. 1-3. 